\title{
Biophysical and physiological causes of coral reef microbialization
}

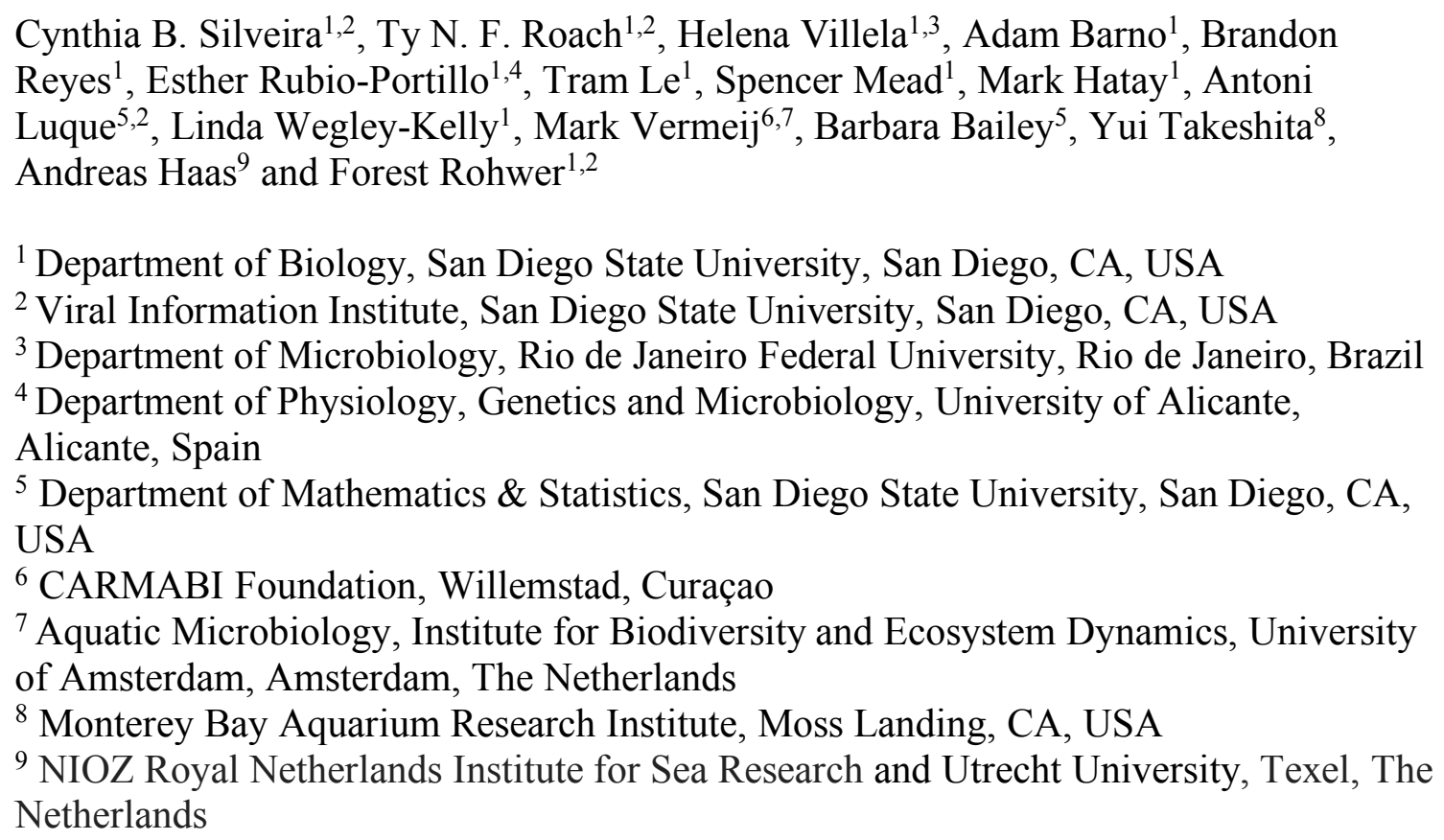

Statement of authorship: CBS, BR, LWK, MH, MV, YT, AH and FR designed experiments and sampling; CBS, TR, HV, BR, ERP, AL, MV, and AH performed experiments; CBS, TR, AB, TL, and SM generated microscopy and metagenomic data; CBS and BB performed statistical analyses; CS wrote the manuscript and all authors contributed substantially with revisions.

\section{Data availability Statement}

Experimental data are provided as supporting datasets and in FigShare (https://doi.org/10.6084/m9.figshare.7170254.v1). Metagenomic data are available in the NCBI SRA under PRJNA494971.

Running title: Coral reef metabolic decoupling

Key words: heterotrophic bacteria, biomass, respiration, carbon metabolism 


\section{Abstract}

47 Coral reefs are declining globally as their primary producer communities shift from stony

48 coral to fleshy macroalgae dominance. Previously, we have shown that the rise of fleshy

49 macroalgae produces dissolved organic carbon (DOC) that lead to microbialization and

50 coral death. Here we test the hypothesis that the biophysical cause of bacterial biomass

51 accumulation is a relative decrease in electron acceptors relative to electron donors due to

$52 \mathrm{O}_{2}$ loss from macroalgae. We show that $37 \%$ of photosynthetic $\mathrm{O}_{2}$ produced by reef

53 fleshy macroalgae is lost in the form of gas through ebullition from algae surfaces. $\mathrm{O}_{2}$

54 loss increases DOC: $\mathrm{O}_{2}$ ratios, decoupling the photosynthetically fixed carbon from

55 oxidative potential for respiration. This biogeochemical environment drives heterotrophic

56 microbes to increase cell-specific DOC consumption and cell sizes, accumulating

57 biomass. In contrast, corals do not lose oxygen and support the growth of smaller and

58 fewer bacteria. In situ biomass and metagenomic analyses of 87 reefs across the Pacific

59 and Caribbean show that on algae-dominated reefs bacteria accumulate organic carbon

60 through a Warburg-like increase in aerobic glycolytic metabolism. Because of its

61 biophysical basis, microbialization is predicted to occur in other marine ecosystems

62 shifting primary producer assemblages, such as planktonic communities in warming and

63 acidifying conditions. 


\section{Introduction}

65

66 Anthropogenic pressures are shifting the composition of reef primary producer

67 communities from calcifying to non-calcifying organisms globally (Cinner et al. 2016;

68 Smith et al. 2016). These changes occur as fleshy algae gain competitive advantage over

69 corals through their interaction with heterotrophic microbes (Barott and Rohwer 2012;

70 Jorissen et al. 2016). High Dissolved Organic Carbon (DOC) release rates by fleshy algae

71 stimulate the growth of the so-called super-heterotrophic bacteria (Haas et al. 2011;

72 Nelson et al. 2013; Kelly et al. 2014). The exacerbated heterotrophic growth at coral-

73 algae interaction zones consume large amounts of oxygen, creating hypoxic zones that

74 kill corals (Haas et al. 2013a; Haas et al. 2014b; Roach et al. 2017). At the reef-scale,

75 shifts from coral to algae dominance stimulate microbial heterotrophic metabolism in the

76 water above the reef (Silveira et al. 2015; Haas et al. 2016; Silveira et al. 2017a). This

77 microbial oxygen consumption creates a feedback loop of coral death, algae overgrowth

78 and microbial biomass accumulation, described as reef microbialization (Dinsdale and

79 Rohwer 2011). Understanding coral reef biomass reallocation into heterotrophic bacterial

80 compartments, in detriment of macro-heterotrophs, requires linking the photosynthesis,

81 respiration, and biomass allocation dynamics during reef degradation (McDole et al.

82 2012; Haas et al. 2016).

83

84 Differences in microbial responses to coral and algae dominance stem from the

85 physiology of these primary producers. Calcifying organisms, including scleractinian

86 corals and crustose coralline algae (CCA), invest 50 to $80 \%$ of their daily fixed carbon in

87 respiration to sustain the energetic costs of calcification (Tremblay et al. 2012). Fleshy

88 macroalgae allocate 10 to $30 \%$ to respiration and release up to $60 \%$ of their primary

89 production as dissolved organic carbon (DOC) (Jokiel and Morrissey 1986; Crossland

90 1987; Cheshire et al. 1996; Peninsula et al. 2007). The ratio between DOC and $\mathrm{O}_{2}$

91 released by fleshy algae in bottle incubations is higher compared to corals (Haas et al.

92 2011; Haas et al. 2013b). Coral and algae physiology would predict the opposite pattern

93 because (a) fleshy algae allocate a higher proportion of their daily synthesized carbon to

94 biomass compared to corals, sustaining high herbivory pressure (Falkowski et al. 1984; 
95 Duarte and Cebrián 1996; Tremblay et al. 2016), and (b) corals allocate higher proportion

96 of their carbon budget to respiration (Hatcher 1988; Houlbrèque and Ferrier-Pagès 2009;

97 Tremblay et al. 2016). Together, these processes are predicted to increase DOC-to- $\mathrm{O}_{2}$

98 ratios in coral exudates compared to algae, but experimental data has shown the opposite

99 to be true (Haas et al. 2011).

100

101 Heterotrophic microbes growing on algal exudates have low growth efficiency, defined

102 as the number of cells produced per unit of carbon consumed (Haas et al. 2011; Nelson et

103 al. 2013; Silveira et al. 2015). Microbes growing on algae-dominated reefs shift their

104 glycolytic metabolism from Embden-Meyerhof-Parnas pathway (EMP) towards Pentose

105 Phosphate (PP) and Entner-Doudoroff (ED) pathways (Haas et al. 2016). All three

106 pathways consume glucose in a series of redox reactions that produce pyruvate. The EMP

107 exclusively produces NADH as reductive potential, while PP and ED store part of the

108 reductive potential in NADPH (Klingner et al. 2015; Spaans et al. 2015). These two

109 reduced coenzymes have different fates in the cell: NADH is mainly used for ATP

110 production via oxidative phosphorylation and NADPH is mainly used for biosynthetic

111 processes (Fuhrer and Sauer 2009). Because oxygen is the final electron acceptor in

112 oxidative phosphorylation, these pathways have distinct $\mathrm{O}_{2}$ consumption patterns.

113 Comparative thermodynamic, kinetic and genomic analyses of these pathways

114 demonstrate that the preferential use of each reflect fundamental thermodynamic and

115 ecological constrains and predicts an impact on the cell metabolic budget (Flamholz et al.

116 2013; Stettner and Segrè 2013).

118 Beyond primary producer physiology, coral reef organic carbon and oxygen dynamics

119 respond to biophysical properties of these organisms and the surrounding environment.

120 Fleshy turf and macroalgae release up to three times more DOC per photosynthetically

121 produced $\mathrm{O}_{2}$ than calcifying organisms (Naumann et al. 2010; Haas et al. 2011; Nelson et

122 al. 2013; Silveira et al. 2015). Yet, algae-dominated systems have consistently lower

123 concentrations of DOC and more extreme daily fluctuations in $\mathrm{O}_{2}$ concentrations

124 (Dinsdale et al. 2008; Martinez et al. 2012; Nelson et al. 2013). Fleshy algae produce $\mathrm{O}_{2}$

125 bubbles through heterogeneous nucleation resulting from $\mathrm{O}_{2}$ super-saturation at the 
126 algae's surface (Kraines et al. 1996). The gaseous $\mathrm{O}_{2}$ in bubbles is not detected by

127 dissolved $\mathrm{O}_{2}$ instruments, causing underestimation of autotrophy in oxygen-based

128 primary productivity methods (Atkinson and Grigg 1984; Kraines et al. 1996). While

129 several studies recognize bubble formation on algal surfaces, the fraction of

130 photosynthetic oxygen lost as bubbles from different benthic primary producers has never

131 been quantified (Odum and Odum 1955; Freeman et al. 2018).

133 Here we test the hypothesis that the relative decrease in electron acceptors relative to

134 electron donors due to $\mathrm{O}_{2}$ loss through ebullition selects for heterotrophic bacterial

135 metabolisms on degraded coral reefs. To answer this question, we developed novel

136 chamber incubation experiments and showed that fleshy macroalgae release larger

137 amounts of photosynthetic $\mathrm{O}_{2}$ by ebullition compared to corals. As $\mathrm{O}_{2}$ comes out of

138 solution, it is no longer available for biological respiration in the water column,

139 increasing the ratio of reducing-to-oxidizing equivalents. We then quantified the

140 microbial physiological responses to these conditions, and observed an in increase in cell

141 volume and organic carbon consumption per cell, and a switch to anabolic metabolism in

142 algae incubations. Finally, we show that the patterns identified in our incubations are

143 observed in situ, with an increase in bacterial biomass and a shift toward anabolic

144 metabolism across 87 reefs in the Pacific and Caribbean. These metabolic transitions are

145 the mechanistic basis of microbialization that intensifies coral reef decline.

\section{Methods}

$149 \mathrm{O}_{2}$ release by benthic primary producers: The rates of dissolved and gaseous $\mathrm{O}_{2}$

150 production by benthic primary producers were measured in two tank experiments (POP

151 Experiments 1 and 2). In both experiments, organisms were incubated in custom-made

152 chambers named peripheral oxygen production (POP) bottles (Figure 1). POP bottles are

153 bell-shaped Polyethylene Terephthalate (PET) bottles with a removable base and two

154 sampling ports, one for dissolved analyte sampling, and one at the top for gas sampling.

155 Primary producers were placed at the bottom and bubbles released from their surfaces

156 during incubation accumulated at the top. Primary producers were placed on the base of 
157 the POP bottles, inside a larger tank filled with reef water. The bell-shaped container was

158 then placed over the base, and the bottle was sealed. At the end of the incubation, the gas

159 accumulated at the top of the bottles was collected in a syringe and the volume of gas was

160 recorded. The gas was transferred to a wide-mouth container and $\mathrm{O}_{2}$ partial pressure was

161 measured using a polarographic probe (Extech 407510) immediately upon collection.

162 Dissolved $\mathrm{O}_{2}$ was determined using a Hatch-Lange HQ40 DO probe.

164 POP Experiment 1: The scleractinian coral Montipora sp. and the fleshy macroalgae

165 Chaetomorpha sp. were collected from coral and macroalgae long-term holding tanks

166 maintained at SDSU. Specimens were collected from the tanks immediately prior to the

167 experiment and placed inside POP bottles. Three specimens of each organism were

168 individually incubated for 4 days with artificial seawater from the coral tank, along with

169 three control bottles under cycles of 12 hours light $\left(125 \mu \mathrm{mol}\right.$ quanta $\left.\mathrm{m}^{-2} \mathrm{~s}^{-1}\right)$ and 12

170 hours dark at $27^{\circ} \mathrm{C}$.

172 POP Experiment 2: Four benthic primary producers were analyzed: the scleractinian

173 coral Orbicella faveolata, CCA, the fleshy macroalgae Chaetomorpha sp., and turf algae.

174 O. faveolata colonies were collected at $12 \mathrm{~m}$ depth from the Water Factory site

$175\left(12^{\circ} 10^{\prime} 91^{\prime \prime} \mathrm{N}, 68^{\circ} 95^{\prime} 49^{\prime}\right.$ W) and cut into $\sim 10 \mathrm{~cm}^{2}$ fragments. Coral fragments were kept

176 for two weeks at the CARMABI Research Station flow-through tank system. The tank

177 was subject to natural diel light cycles with light intensities comparable to $10 \mathrm{~m}$ depth, as

178 measured using HOBO Pendant UA-002-64. CCA, turf, and macroalgae were collected

179 off CARMABI immediately prior to the experiment. Five individual incubations for each

180 organism were conducted. Surface area of organisms are provided in Supplementary

181 Dataset 1 . Incubations lasted for 2 days at $24^{\circ} \mathrm{C}$ with natural diel light cycles.

183 Bacterial growth on primary producer exudates: Bacterial growth data, including

184 changes in abundance, cell size and total microbial biomass, derived from three

185 independent experiments: POP Experiment 2, Experiments 3 and 4 (Figure 1). Details on

186 each one of these datasets are given below: 
188 POP Experiment 2: At the start and end of the incubation (time $0 \mathrm{~h}$ and $48 \mathrm{~h}$ ), $1 \mathrm{~mL}$

189 samples were collected and analyzed by fluorescence microscopy according to McDole et

190 al. 2012. Briefly, cell volume was calculated by considering all cells to be cylinders with

191 hemispherical caps and individual microbial cell volumes were converted to mass in wet

192 and dry weight using previously established size-dependent relationships for marine

193 microbial communities (Simon and Azam 1989). Differences in cell abundance, cell

194 volume, and total microbial biomass were calculated by the difference between final and

195 initial values.

197 Experiment 3: Five specimens of the coral Favia sp. were obtained from a long-term

198 holding tank at the Hawaiian Institute of Marine Biology (HIMB) and placed in

199 independent $5 \mathrm{~L}$ polycarbonate containers filled with $0.2 \mu \mathrm{m}$-filtered seawater. Five

200 specimens of the fleshy macroalgae Gracilaria sp. were collected off HIMB and placed

201 in independent $5 \mathrm{~L}$ containers. Additional control containers were filled with filtered

202 seawater. Primary producers were incubated in natural light conditions for 8 hours to

203 release exudates. At the end of the incubation, $2 \mathrm{~L}$ of seawater containing exudates were

$2040.2 \mu \mathrm{m}$-filtered and inoculated with $1 \mathrm{~L}$ of unfiltered offshore seawater containing water

205 column reef microbial communities. All bottles were incubated for 24 hours in the dark.

206 For microbial abundance and biomass determination, $1 \mathrm{~mL}$ samples were collected and

207 analyzed as described above. Differences in cell abundance, cell volume and total

208 heterotrophic microbial biomass were calculated by the difference between final and

209 initial values.

210

211 Experiment 4: This dark incubation experiment was performed in 2010 in Mo'orea,

212 French Polynesia. The data was first published in Haas et al. 2011 and was re-analyzed

213 here to investigate cell-specific carbon and $\mathrm{O}_{2}$ consumption. Briefly, exudates from

214 corals and algae released during a light incubation period were $0.2 \mu \mathrm{m}$-filtered and

215 inoculated with reef microbes. Inoculation in filtered seawater was utilized as control. All

216 bottles were kept in the dark for 48 hours. DOC, dissolved $\mathrm{O}_{2}$ and microbial abundances

217 were measured at the beginning and at the end of each dark incubation as described

218 above. DOC samples were filtered through pre-combusted GF/F filters (Whatman, 0.7 
$219 \mu \mathrm{m}$ nominal particle retention) and transferred to acid-washed HDPE vials. Samples were

220 kept frozen until analysis according to Carlson et al. 2010 (Carlson et al. 2010). DOC and

$221 \mathrm{O}_{2}$ consumption rates normalized by the bacterial cell yield at the end of each experiment

222 resulted in cell-specific carbon and $\mathrm{O}_{2}$ demands. The fleshy organisms used in this

223 experiment were turf algae and the macroalgae Turbinaria ornata and Amansia

224 rhodantha, and the calcifying organisms were CCA and the coral Porites lobata.

226 Central carbon metabolism pathways: Microbial metagenomes were sequenced from

227 water samples collected on coral reefs in the Pacific and in the Caribbean. The Pacific

228 samples were collected during NOAA RAMP cruises from 2012-2014 to Hawaiian

229 Islands, Line Islands, American Samoa, and Phoenix Islands. Caribbean samples were

230 collected around the island of Curaçao during the Waitt Institute Blue Halo expedition in

231 2015. Geographic coordinates for each sampling site are provided in Supplementary

232 Dataset 5, along with benthic cover data. At each sampling site SCUBA divers collected

233 water from within $30 \mathrm{~cm}$ of the reef surface using Hatay-Niskin bottles (Haas et al.

234 2014a). Samples were brought to the ship, filtered through a $0.22 \mu \mathrm{m}$ cylindrical filter

235 within 4 hours, and stored at $-20{ }^{\circ} \mathrm{C}$ until laboratory processing. DNA was extracted from

236 the filters using Nucleospin Tissue Extraction kits (Macherey Nagel, Germany) and

237 sequenced on an Illumina HiSeq platform (Illumina, USA). Pacific microbial

238 metagenomes described here were previously analyzed for the presence of CRISPR

239 elements, competence genes and Shannon diversity in Knowles, Silveira et al. 2016.

240 Original fastq files from Pacific and Curaçao metagenomes were quality filtered in

241 BBTools with quality score $>20$, duplicate removal, minimum length of 60 bases, and

242 entropy 0.7 (Bushnell 2014). The metagenomes are available on the NCBI Short Read

243 Archive (PRJNA494971). Relative abundances of genes encoding rate-limiting enzymes

244 in central carbon metabolism pathways were utilized as proxy for the representation of

245 that pathway in the community. The list of pathways and enzymes analyzed here is

246 provided in Supplementary Table 1. Enzyme-specific databases were built using amino

247 acid sequences from the NCBI bacterial RefSeq. BLASTx searches were performed using

248 metagenomic reads against each enzyme database, using a minimum alignment length of

24940 , minimum identity of $60 \%$ and e-value $<10^{-5}$. Reads mapping to the database were 
250 normalized by total high-quality reads resulting in the percent abundance of each

251 enzyme. Relative gene abundances are provided as Supplementary Dataset 5. Abundance

252 of bacterial genera in metagenomes were generated through k-mer profiles using

253 FOCUS2 (Silva et al. 2016).

255 Statistical tests: All statistical analyses were performed using the software R. The

256 response variables from the incubation experiments were tested for normality using the

257 Shapiro-Wilk test. Due to lack of normality (Shapiro-Wilk, $\mathrm{p}<0.05$ ), the nonparametric

258 Kruskal-Wallis test was used to test if there were differences in treatments followed by

259 the post-hoc Wilcoxon test with the False Discovery Rate (FDR) correction with a

260 significance cutoff of $\mathrm{p}<0.05$. Because gaseous $\mathrm{O}_{2}$ production and fraction of total $\mathrm{O}_{2}$ in

261 the form of gas were not significantly different between POP Experiments 1 and 2

262 (Kruskal-Wallis, $\mathrm{p}>0.05$ ), we combined the results of both experiments in subsequent

263 tests. For analysis of in situ data, microbial biomass was log-transformed to meet the

264 assumption of normality for testing the significance of the slope in the linear regression

265 of fleshy algae cover on microbial biomass. The relationships between fleshy algae cover

266 and enzyme abundances or taxonomic profiles were analyzed by the statistical learning

267 method of supervised random forests. The significance of the random forests variable

268 importance was determined by a permutation method applied to the supervised random

269 forests using the R package rfPermute.

270

\section{Results}

272

273 One third of algal photosynthetic $\mathrm{O}_{2}$ is lost as gas: We designed new incubation

274 chambers called POP (Peripheral Oxygen Production) bottles to quantify the dissolved

275 and gaseous $\mathrm{O}_{2}$ release from coral reef primary producers (Figure 1). Dissolved $\mathrm{O}_{2}$

276 production was significantly different among primary producer treatments (Figure 2A,

277 Kruskal-Wallis $\chi^{2}(4)=19.5, \mathrm{p}<0.05$, Supplementary Dataset 1). Primary producers

278 showed higher dissolved $\mathrm{O}_{2}$ production compared to controls (Wilcoxon $\mathrm{p}<0.05$ for all

279 FDR-corrected pairwise comparisons against control). Dissolved $\mathrm{O}_{2}$ production was

280 highly variable and not significantly different between fleshy and calcifying organisms 
$281 \quad\left(5.99 \pm 2.29\right.$ and $6.33 \pm 2.20 \mu \mathrm{mol} \mathrm{cm}^{-2}$ day $^{-1}$ for fleshy and calcifying, respectively,

282 mean $\pm \mathrm{SE}$; Wilcoxon $\mathrm{p}>0.05$ ). Gaseous $\mathrm{O}_{2}$ production was observed in most primary

283 producer bottles, while no gas was observed in control bottles (Figure 2B, Kruskal-Wallis

$284 \chi^{2}(4)=30.2, p<0.05$, Wilcoxon $\mathrm{p}<0.05$ for all pairwise comparisons against control).

285 Fleshy organisms combined produced significantly more gaseous $\mathrm{O}_{2}$ than calcifying

$286\left(0.42 \pm 0.35\right.$ and $2.33 \pm 1.35 \mu \mathrm{mol} \mathrm{cm}^{-2}$ day $^{-1}$ for calcifying and fleshy, respectively,

287 mean $\pm \mathrm{SE}$; Wilcoxon $\mathrm{p}<0.05)$. Fleshy macroalgae had the highest fraction of total

288 photosynthetic $\mathrm{O}_{2}$ (sum of dissolved and gaseous $\mathrm{O}_{2}$ ) released in the form of gas $(37.33 \pm$

$2898.34 \%)$, followed by turf algae $(13.78 \pm 1.33 \%)$, CCA $(10.19 \pm 2.88 \%)$, and corals

$290(5.00 \pm 5.55 \%)$ (Figure 2C). The difference in the fraction of $\mathrm{O}_{2}$ as gas was significant

291 among treatments (Kruskal-Wallis $\left.\chi^{2}(4)=29.2, \mathrm{p}<0.05\right)$ and higher in fleshy organisms

292 (Kruskal-Wallis $\chi^{2}(2)=26.3, \mathrm{p}<0.05$; Wilcoxon $\mathrm{p}<0.05$ for fleshy vs calcifying).

294 Bacteria accumulate more carbon under high DOC: $\mathrm{O}_{2}$ : During POP Experiments, the

295 change in bacterial abundance in primary producer bottles was higher compared to

296 controls (Figure 3A, Kruskal-Wallis $\chi^{2}(4)=20.6, p<0.05$, Wilcoxon $p<0.05$ for all

297 pairwise comparisons against control, Supplementary Dataset 2). The change in

298 abundance was higher in fleshy algae treatments compared to calcifying treatments

299 (Kruskal-Wallis $\chi^{2}(2)=16.4, p<0.05$, Wilcoxon $\mathrm{p}<0.05$ for pairwise comparison of

300 fleshy vs calcifying). Microbial cell volume changed differently in treatments during

301 incubations (Figure 3B, Kruskal-Wallis $\mathrm{x}^{2}(5)=1235.2, \mathrm{p}<0.05$, Supplementary Dataset

302 3). Bacteria growing in control bottles showed no change in volume (Wilcoxon, $\mathrm{p}>0.05$

303 for pairwise comparison of control vs T0h). When growing on coral and CCA exudates,

304 bacteria became smaller, while growing on turf and macroalgae exudates lead to an

305 increase in bacterial cell volume (Wilcoxon $\mathrm{p}<0.05$ for all pairwise comparisons vs T0h

306 and vs control). When taking abundance and cell volume into account, the change in total

307 bacterial biomass was significantly different among treatments (Figure 3C, Kruskal-

308 Wallis $\chi^{2}(4)=21.6, p<0.05$, Supplementary Dataset 2). Coral exudates decreased total

309 bacterial biomass, while turf and macroalgae increased total bacterial biomass, and CCA

310 lead to no change (Wilcoxon, $\mathrm{p}<0.05$ for pairwise comparisons of coral, turf and 
311 macroalgae vs control). The change in biomass in the two fleshy algae together was

312 greater than in the calcifying organisms together (Kruskal-Wallis $\chi^{2}(2)=16.6, p<0.05$;

313 Wilcoxon, $\mathrm{p}<0.05$ for pairwise comparison of fleshy vs calcifying).

315 A bottle incubation performed at the Hawaiian Institute of Marine Biology (HIMB) with

316 a distinct set of primary producers showed the same pattern in microbial physiology

317 (Experiment 3, Supplementary Datasets 2 and 3). After 24 hours of dark incubation on

318 exudates but in the absence of primary producer, microbial abundances increased in both

319 the coral and algae treatments (Figure S1A, Kruskal-Wallis $\chi^{2}(2)=7.2, p<0.05$ ).

320 Changes in cell volume were not significant among treatments (Figure S1B, Kruskal-

321 Wallis $\left.\chi^{2}(2)=3.8, p>0.05\right)$. However, the resulting change in total microbial biomass

322 when accounting for cell volume and abundance showed an increase in biomass in

323 macroalgae treatments, while coral treatments did not change and controls decreased in

324 biomass (Kruskal-Wallis $\left.\chi^{2}(2)=7.2, p<0.05\right)$.

Bacteria decouple DOC and $\mathrm{O}_{2}$ consumption: Cell-specific carbon and $\mathrm{O}_{2}$ consumption

327 by heterotrophic metabolism was obtained by normalizing the change in DOC and $\mathrm{O}_{2}$

328 concentrations by the cell yield in a dark incubation (Experiment 4 in Figure 1,

329 Supplementary Dataset 4). The amount of DOC consumed per cell was higher in fleshy

330 macroalgae treatments compared to coral and control treatments (i.e., low cell yields per

331 carbon consumed, Figure 4A, Kruskal-Wallis $\chi^{2}(2)=13.7, p<0.05$; Wilcoxon, $p<0.05$

332 for pairwise comparisons of macroalgae vs controls and vs corals). The amount of $\mathrm{O}_{2}$

333 consumed per cell was not different between treatments (Figure 4B, Kruskal-Wallis $\chi^{2}(2)$

$334=0.5, \mathrm{p}>0.05)$.

336 Warburg-like metabolism causes bacterial biomass accumulation: The relative

337 abundance of genes encoding rate-limiting enzymes of central carbon metabolism

338 pathways was quantified in microbial metagenomes from reefs across a gradient in algae

339 cover (Supplementary Dataset 5). In this dataset, water column microbial biomass

340 increased with fleshy algae cover (Linear regression, $\mathrm{p}<0.05, \mathrm{~m}=0.009, \mathrm{R}^{2}=0.29$ for

341 the comparison between $\log _{10}$-transformed biomass and fleshy algae cover). The random 
342 forest analysis with genes encoding rate-limiting enzymes of central carbon metabolism

343 explained $14.3 \%$ of the fleshy algae cover. The genes with highest explanatory power

344 were phosphoenolpyruvate carboxylase, aspartate aminotransferase, oxoglutarate

345 dehydrogenase, glucose 6-phosphate dehydrogenase and KDPG aldolase (increasing

346 mean squared error $15.78,9.73,9.21,8.70$ and $6.95 \%$, respectively). The relationships

347 between these enzymes and fleshy algae cover are shown in Figure 5.

348 Phosphoenolpyruvate carboxylase and aspartate aminotransferase are involved in

349 anaplerotic reactions, glucose 6-phosphate dehydrogenase diverts glucose to both Entner-

350 Doudoroff and Pentose Phosphate pathways, and KDPG aldolase is unique to the Entner-

351 Doudoroff pathway. These four enzymes had a positive relationship with fleshy algae

352 cover (random forest mean decreasing accuracy, $\mathrm{p}<0.05$ ). Oxoglutarate dehydrogenase

353 is an oxidative enzyme in the Krebs cycle, and its relative abundance decreased with

354 fleshy algae cover (random forest mean decreasing accuracy, $\mathrm{p}<0.05$ ).

356 To test if these changes in relative gene abundances could be explained by the taxonomic

357 dominance of bacterial genera encoding these genes, we tested the relationship between

358 fleshy algae cover and taxonomic profiles at the genus level using random forest. While

359 several taxonomic groups changed their abundance with increasing fleshy algae cover,

360 none of these groups consistently lack or encode the enzymes of the central carbon

361 pathways described here, with high strain-level variation in their functional genetic

362 repertoire (Supplementary Dataset 5 shows the relative abundances of genera with

363 significant relationship with fleshy algae cover in the random forest mean decreasing

364 accuracy, $\mathrm{p}<0.05)$.

365

\section{Discussion}

$368 \mathrm{O}_{2}$ ebullition modifies reef biogeochemistry: Photosynthesis and respiration have a

369 theoretical 1:1 molar ratio of carbon and $\mathrm{O}_{2}$ produced and consumed (Williams et al.

370 1979). In holobionts with a large heterotrophic component, such as corals, respiration

371 consumes at least $50 \%$ of the oxygen and organic carbon produced in photosynthesis

372 (Tremblay et al. 2016). Respiration quotients for symbiotic cnidarians range from 0.8 and 
3730.9 , consuming more $\mathrm{O}_{2}$ than carbon (Muscatine et al. 1981). Based on these processes,

374 the higher ratios of DOC: $\mathrm{O}_{2}$ observed in fleshy algal exudates compared to corals are

375 counter-intuitive (Haas et al. 2011). $\mathrm{O}_{2}$ ebullition is a plausible explanation for this

376 observation. The organic carbon released by algae stays in solution, while a fraction of

377 the $\mathrm{O}_{2}$ nucleates and escapes, leaving behind a high DOC:dissolved $\mathrm{O}_{2}$ ratio. Differential

378 carbon allocation into biomass can also alter these ratios, and the quantitative analysis of

379 carbon incorporation in combination with dissolved and gaseous $\mathrm{O}_{2}$ dynamics is the next

380 step to resolve these budgets.

381

$382 \mathrm{O}_{2}$ ebullition and bubble injection by hydrodynamics are recognized as a source of error

383 when estimating production in shallow water ecosystems, yet the extent to which

384 ebullition affects these estimates is rarely quantified due to methodological challenges

385 (Kraines et al. 1996; Cheng et al. 2014). $\mathrm{O}_{2}$ ebullition observed in this study

386 corresponded to $5-37 \%$ of net primary production and accounted for the loss of up to

38721 and $37 \%$ of photosynthetically produced $\mathrm{O}_{2}$ in a salt marsh and a lake, respectively

388 (Koschorreck et al. 2017; Howard et al. 2018). If in situ bubble nucleation and rise rates

389 are comparable to those in incubations, our results imply that coral reef primary

390 production has been significantly underestimated (Howard et al. 2018). In coral reefs,

391 bubbles were reported on the surface of turf algae, on sediments, and inside coral

392 skeletons colonized by endolithic algae (Odum and Odum 1955; Bellamy and Risk 1982;

393 Clavier et al. 2008; Freeman et al. 2018). The heterogeneous distribution of bubble

394 nucleation over primary producers entail that benthic community compositional shifts

395 determine the magnitude of $\mathrm{O}_{2}$ ebullition on reef-level $\mathrm{O}_{2}$ dynamics. A combination of in

396 situ incubations and gas exchange studies is required to establish such relationships.

398 Warburg effect is the biophysical mechanism of microbialization: High DOC: $\mathrm{O}_{2}$ release

399 ratio by algae reflect bacterial carbon and oxygen metabolism. When growing on algal

400 exudates, microbes increased cell volume and DOC consumption per cell (Figure 3 and

401 4A). These cells displayed the same cell-specific $\mathrm{O}_{2}$ consumption compared to small cells

402 growing on coral exudates (Figure 4B). These results indicated that microbes growing on

403 coral exudates fully oxidize the organic carbon consumed, channeling metabolic energy 
404 to maintenance costs (Russell and Cook 1995). On algal exudates, bacteria had higher

405 cell-specific DOC consumption, with greater fraction of the organic carbon shunted to

406 biosynthesis (incomplete oxidation), and less relative $\mathrm{O}_{2}$ consumption, culminating in

407 increased community biomass. This process is classically described as the Warburg effect

408 in eukaryotic cells undergoing fast metabolism and limited by the enzyme catalytic rates,

409 as opposed to substrate concentrations (Vander Heiden et al. 2009). In bacteria, the

410 Warburg effect is a physiological response that optimizes energy biogenesis and biomass

411 synthesis in face of changing proteomic demands (Basan et al. 2015). This biochemical

412 transition occurs because the proteome cost of energy biogenesis by respiration exceeds

413 that by fermentation.

415 The decoupling between bacterial specific carbon and $\mathrm{O}_{2}$ consumption observed in

416 Figure 4 predicts an increase in pathways that shunt carbon to biosynthesis and

417 incomplete oxidation when bacteria are growing on algal exudates (Russell and Cook

418 1995; Haas et al. 2016). The Pentose Phosphate (PP) and Entner-Doudoroff (ED)

419 pathways are alternatives to the canonical glycolytic route for carbohydrate consumption

420 (Embden-Meyerhoff-Parnas, EMP). Both PP and ED produce more NADPH than

421 NADH. These two reduced coenzymes have distinct functions: NADPH is preferentially

422 consumed in biosynthetic routes for lipid, amino acid, and nucleotide synthesis while

423 NADH is preferentially consumed in oxidative phosphorylation for ATP production

424 (Pollak et al. 2007; Spaans et al. 2015). Therefore, cells utilizing more NADH pathways

425 will consume more $\mathrm{O}_{2}$ relative to carbon compared to cells utilizing more NADPH. Our

426 metagenomic data is in line with this prediction. The abundance of genes encoding

427 glucose-6-phosphate dehydrogenase and KDPG aldolase increased with fleshy algae

428 cover (Figure 5). Glucose-6-phosphate dehydrogenase deviates glucose to both the PP

429 and ED pathways, and KDPG aldolase is unique to ED.

431 The tricarboxylic acid cycle (TCA or Krebs cycle), is a canonically oxidative path for 432 complete decarboxylation of pyruvate. But the TCA cycle can work as a biosynthetic 433 pathway by providing intermediates to amino acids, nitrogenous bases and fatty acids 434 syntheses (Sauer and Eikmanns 2005; Cronan and Laporte 2013). TCA cycle 
435 stoichiometry is maintained through the resupply of these intermediates by anaplerotic

436 reactions that use pyruvate (or phosphoenolpyruvate) (Owen et al. 2002). Here we found

437 an increase in the abundance of genes encoding anaplerotic enzymes and decrease in

438 genes encoding oxoglutarate dehydrogenase, catalyzes an oxidative decarboxylation in

439 the Krebs cycle, with increasing algal cover. These results indicate a shift towards the use

440 of Krebs cycle as an anabolic route (Sauer and Eikmanns 2005; Bott 2007). Anaplerotic

441 activity increases in rapidly growing bacteria with high rates of amino-acid synthesis

442 (Bott 2007). These routes shunt organic carbon into biomass accumulation, as opposed to

443 oxidation with electron transfer to $\mathrm{O}_{2}$ (Russell and Cook 1995). This is consistent with the

444 bacterial growth and DOC consumption patterns observed in our incubation experiments.

446 Alternative hypotheses for DOC and $\mathrm{O}_{2}$ consumption patterns are broken TCA cycles and 447 reactive oxygen species (ROS) detoxification (Mailloux et al. 2007; Steinhauser et al.

448 2012). There was no evidence for an increase in genes encoding these pathways in our

449 dataset (Supplementary Data 5). The metagenomic transitions observed cannot be

450 explained by the rise or disappearance of specific taxonomic groups associated with

451 microbialization, such as Vibrio, Flavobacteria and SAR11 (Dinsdale et al. 2008; Kelly

452 et al. 2014). The genes encoding the pathways discussed here are not consistently

453 encoded by these taxonomic groups, and the functional genomic transitions observed here

454 are likely a result of strain-level compositional shifts not directly related to the taxonomic

455 structure of the community at genus or family level, as is often the case for coral reefs

456 (Klingner et al. 2015; Silveira et al. 2017b).

$458 \mathrm{O}_{2}$ loss affects ecosystem biomass allocation: $\mathrm{O}_{2}$ depletion observed in previous dark

459 incubations with algae exudates was a result of high bacterial densities, and not of high

460 cell-specific respiration rates (Haas et al. 2016). The cell volume and abundance changes

461 observed in our experiments explain in situ microbial biomass (McDole et al. 2012; Haas

462 et al. 2016). In degraded reefs, fleshy algae release more exudates than corals,

463 fundamentally modifying the biogeochemical environment for heterotrophic metabolism

464 (Figure 6). The ensuing increases in bacterial size, abundance and DOC consumption

465 described in our incubations make bacterial energetic demands surpass that of macrobes, 
466 and explain the observed decrease in DOC standing stocks in degraded reefs (McDole et

467 al. 2012; Haas et al. 2016; Somera et al. 2016). Increase in overflow metabolism due to

468 the decoupling between anabolic and catabolic reactions is consistent with the high

469 amounts of particulate material observed in algae-dominated reefs, affecting reef-scale

470 trophic interactions (Russell and Cook 1995; Wilson et al. 2003; De'ath and Fabricius

471 2010; Silveira et al. 2015; Haas et al. 2016). The metabolic decoupling described here is

472 also likely to occur in planktonic oceanic systems in response to global changes: warmer,

473 high $\mathrm{pCO}_{2}$ waters depleted of nutrients due to stratification shift primary producer

474 community composition, increasing the release of carbon-rich exudates by phytoplankton

475 while decreasing $\mathrm{O}_{2}$ (Boyd et al. 2010; Oschlies et al. 2018). Pelagic heterotrophic

476 bacterial metabolism display a positive relationship between substrate energy density and

477 turnover times, with no relationship with respiration rates (Casey et al. 2015). This

478 pattern is consistent with metabolic shifts described here, decreasing microbial biomass

479 turnover rates in the oceans (Vallino et al. 1996).

\section{Conclusion}

482

483 Ebullition causes a decoupling between photosynthetic fixed carbon and $\mathrm{O}_{2}$ in fleshy

484 macroalgae. The $\mathrm{O}_{2}$ loss by ebullition fundamentally changes the reef biogeochemical

485 environment. In contrast, there is almost no $\mathrm{O}_{2}$ loss through ebullition associated with

486 corals, because the zooxanthellae reside in the tissue of the animal. On reefs with large

487 amounts of fleshy macroalgae, the microbial community is dominated by anabolic

488 metabolisms, with corresponding increases in cell volume, abundance and specific DOC

489 consumption pathways. These physiological changes cause microbial biomass

490 accumulation with detrimental effects on coral health and trophic relationships.

\section{Acknowledgements}

493 We thank the crew and captain of the NOAA ship Hi'ialakai and Waitt Institute ship Plan

494 B that contributed to sampling. We thank the CARMABI and HIMB teams for the

495 support conducting field experiments. We thank Robert Edwards at SDSU for access to

496 computer servers funded by the NSF (CNS-1305112 to Robert A. Edwards). This work 
497 was funded by the Gordon and Betty Moore Foundation (grant 3781 to FR), Spruance

498 Foundation, NOAA, and the Waitt Institute. CBS was funded by CNPq (234702 to CBS)

499 and Spruance Foundation. TNFR was supported by the NSF (G00009988 to TNFR).

500

\section{Conflict of interest statement}

502 The authors declare no conflict of interest. 


\section{References}

504

505 Atkinson MJ, Grigg RW (1984) Model of a Coral Reef Ecosystem. Coral Reefs 3:13-22.

506 Barott KL, Rohwer FL (2012) Unseen players shape benthic competition on coral reefs.

507 Trends in Microbiology 20:621-628. doi: 10.1016/j.tim.2012.08.004

508 Basan M, Hui S, Okano H, et al (2015) Overflow metabolism in Escherichia coli results

509 from efficient proteome allocation. Nature 528:99.

510 Bellamy N, Risk MJ (1982) Coral gas: oxygen production in Millepora on the Great

$511 \quad$ Barrier Reef. Science 215:1618-1619.

512 Bott M (2007) Offering surprises: TCA cycle regulation in Corynebacterium glutamicum.

513 Trends in Microbiology 15:417-425.

514 Boyd PW, Strzepek R, Fu F, Hutchins D a. (2010) Environmental control of open-ocean

515 phytoplankton groups: Now and in the future. Limnology and Oceanography

$516 \quad$ 55:1353-1376. doi: 10.4319/1o.2010.55.3.1353

517 Bushnell B (2014) BBTools software package.

518 Carlson CA, Hansell DA, Nelson NB, et al (2010) Dissolved organic carbon export and

519 subsequent remineralization in the mesopelagic and bathypelagic realms of the

520 North Atlantic basin. Deep Sea Research Part II: Topical Studies in Oceanography

$521 \quad 57: 1433-1445$.

522 Casey JR, Falkowski PG, Karl DM (2015) Substrate selection for heterotrophic bacterial

523 growth in the sea. Marine Chemistry 177:349-356. doi:

$524 \quad$ 10.1016/j.marchem.2015.06.032

525 Cheng CH, Huettel M, Wildman RA (2014) Ebullition-enhanced solute transport in

526 coarse-grained sediments. Limnology and Oceanography 59:1733-1748.

527 Cheshire AC, Westphalen G, Wenden A, et al (1996) Photosynthesis and respiration of

528 phaeophycean-dominated macroalgal communities in summer and winter. Aquatic

529 Botany 55:159-170.

530 Cinner JE, Huchery C, Macneil MA, et al (2016) Bright spots among the world's coral

531 reefs. Nature 535:416-419. doi: 10.1038/nature18607

532 Clavier J, Chauvaud L, Cuet P, et al (2008) Diel variation of benthic respiration in a coral

533 reef sediment (Reunion Island, Indian Ocean). Estuarine, Coastal and Shelf Science 
$76: 369-377$.

535 Cronan JE, Laporte D (2013) Tricarboxylic Acid Cycle and Glyoxylate Bypass. EcoSal

536 Plus 1-23. doi: 10.1128/ecosalplus.3.5.2

537 Crossland CJ (1987) In situ release of mucus and DOC-lipid from the corals Acropora

538 variabilis and Stylophora pistillata in different light regimes. Coral Reefs 6:35-42.

539 doi: $10.1007 / \mathrm{BF} 00302210$

540 De'ath G, Fabricius K (2010) Water quality as a regional driver of coral biodiversity and

541 macroalgae on the Great Barrier Reef. Ecological Applications 20:840-850.

542 Dinsdale EA, Pantos O, Smriga S, et al (2008) Microbial ecology of four coral atolls in

543 the Northern Line Islands. PLoS ONE 3:e15841-17. doi:

$544 \quad$ 10.1371/journal.pone.0001584

545 Dinsdale EA, Rohwer F (2011) Fish or Germs? Microbial Dynamics Associated with

546 Changing Trophic Structures on Coral Reefs. 231-240. doi: 10.1007/978-94-007-

547 0114-4_16

548 Duarte CM, Cebrián J (1996) The fate of marine autotrophic production. Limnology and 549 Oceanography 41:1758-1766.

550 Falkowski PG, Dubinsky Z, Muscatine L, Porter JW (1984) Light and bioenergetics of a 551 symbiotic coral. BioScience 34:705-709.

552 Flamholz A, Noor E, Bar-Even A, et al (2013) Glycolytic strategy as a tradeoff between energy yield and protein cost. Proceedings of the National Academy of Sciences

555 Freeman SE, Freeman LA, Giorli G, Haas AF (2018) Photosynthesis by marine algae

556 produces sound, contributing to the daytime soundscape on coral reefs. PloS one $557 \quad 13: \mathrm{e} 0201766$.

558 Fuhrer T, Sauer U (2009) Different biochemical mechanisms ensure network-wide

559 balancing of reducing equivalents in microbial metabolism. Journal of Bacteriology 560 191:2112-2121. doi: 10.1128/JB.01523-08

561 Haas AF, Fairoz MFMFM, Kelly LWLW, et al (2016) Global microbialization of coral

562 reefs. Nature Microbiology 1:16042. doi: 10.1038/nmicrobiol.2016.42

563 Haas AF, Gregg AK, Smith JE, et al (2013a) Visualization of oxygen distribution

564 patterns caused by coral and algae. PeerJ 1:e106. 
565 Haas AF, Knowles B, Lim YW, et al (2014a) Unraveling the unseen players in the ocean

566

567

568

569

570

571

572

573

574

575

576

577

578

579

580

581

582

583

584

585

586

587

588

589

590

591

592

593

594

595

- a field guide to water chemistry and marine microbiology. Journal of visualized experiments : JoVE 21:1-16. doi: 10.3791/52131

Haas AF, Nelson CE, Rohwer F, et al (2013b) Influence of coral and algal exudates on microbially mediated reef metabolism. PeerJ 1:e108. doi: 10.7717/peerj.108

Haas AF, Nelson CE, Wegley Kelly L, et al (2011) Effects of coral reef benthic primary producers on dissolved organic carbon and microbial activity. PLoS ONE 6:e27973. doi: 10.1371/journal.pone.0027973

Haas AF, Smith JE, Thompson M, Deheyn DD (2014b) Effects of reduced dissolved oxygen concentrations on physiology and fluorescence of hermatypic corals and benthic algae. PeerJ 2:e235.

Hatcher BG (1988) Coral reef primary productivity: A beggar's banquet. Trends in Ecology \& Evolution 3:106-11. doi: 10.1016/0169-5347(88)90117-6

Houlbrèque F, Ferrier-Pagès C (2009) Heterotrophy in tropical scleractinian corals. Biological reviews of the Cambridge Philosophical Society 84:1-17. doi: 10.1111/j.1469-185X.2008.00058.x

Howard EM, Forbrich I, Giblin AE, et al (2018) Using noble gases to compare parameterizations of air-water gas exchange and to constrain oxygen losses by ebullition in a shallow aquatic environment. Journal of Geophysical Research: Biogeosciences 123:2711-2726.

Jokiel PL, Morrissey JI (1986) Influence of size on primary production in the reef coral Pocilopora damicornis and the macroalga Acanthophora spicifera. Marine Biology 91:15-26.

Jorissen H, Skinner C, Osinga R, et al (2016) Evidence for water-mediated mechanisms in coral - algal interactions. Proceedings of the Royal Society B: Biological Sciences 283:20161137. doi: 10.1098/rspb.2016.1137

Kelly LW, Williams GJ, Barott KL, et al (2014) Local genomic adaptation of coral reefassociated microbiomes to gradients of natural variability and anthropogenic stressors. Proceedings of the National Academy of Sciences 111:10227-10232. doi: $10.1073 /$ pnas. 1403319111

Klingner A, Bartsch A, Dogs M, et al (2015) Large-scale 13C flux profiling reveals 
conservation of the Entner-Doudoroff Pathway as a glycolytic strategy among marine bacteria that use glucose. Applied and Environmental Microbiology 81:2408-2422. doi: 10.1128/AEM.03157-14

Knowles B, Silveira C, Bailey B, et al (2016) Lytic to temperate switching of viral

601 Koschorreck M, Hentschel I, Boehrer B (2017) Oxygen ebullition from lakes.

602 Geophysical Research Letters 44:9372-9378.

603 Kraines S, Suzuki Y, Yamada K, Komiyama H (1996) Separating biological and physical

604 changes in dissolved oxygen concentration in a coral reef. Limnology and

605 Oceanography 41:1790-1799.

606 Mailloux RJ, Bériault R, Lemire J, et al (2007) The tricarboxylic acid cycle, an ancient

607 metabolic network with a novel twist. PLoS ONE 2:e690. doi:

$608 \quad$ 10.1371/journal.pone.0000690

609 Martinez JA, Smith CM, Richmond RH (2012) Invasive algal mats degrade coral reef 610 physical habitat quality. Estuarine, Coastal and Shelf Science 99:42-49. doi:

$611 \quad$ 10.1016/j.ecss.2011.12.022

612 McDole T, Nulton J, Barott K, et al (2012) Assessing coral reefs on a Pacific-wide scale 613 using the microbialization score. PLoS One 7:e432331-10. doi:

$614 \quad$ 10.1371/journal.pone.0043233

615 Muscatine L, R. McCloskey L, E. Marian R (1981) Estimating the daily contribution of

616 carbon from zooxanthellae to coral animal respiration. Limnology and oceanography $617 \quad 26: 601-611$.

618 Naumann MS, Mayr C, Struck U, Wild C (2010) Coral mucus stable isotope composition 619 and labeling: experimental evidence for mucus uptake by epizoic acoelomorph 620 worms. Marine Biology 157:2521-2531. doi: 10.1007/s00227-010-1516-3

621 Nelson CE, Goldberg SJ, Wegley Kelly L, et al (2013) Coral and macroalgal exudates 622 vary in neutral sugar composition and differentially enrich reef bacterioplankton 623 lineages. The ISME journal 7:962-79. doi: 10.1038/ismej.2012.161

624 Odum HT, Odum EP (1955) Trophic structure and productivity of a windward coral reef 625 community on Eniwetok Atoll. Ecological Monographs 25:291-320.

626 Oschlies A, Brandt P, Stramma L, Schmidtko S (2018) Drivers and mechanisms of ocean 
deoxygenation. Nature Geoscience 1:1.

628 Owen OE, Kalhan SC, Hanson RW (2002) The key role of anaplerosis and cataplerosis

629 for citric acid cycle function. Journal of Biological Chemistry 277:30409-30412.

630 doi: $10.1074 /$ jbc.R200006200

631 Peninsula I, Wada S, Aoki MN, et al (2007) Quantitative and qualitative analyses of

632 dissolved organic matter released from Ecklonia cava, Kjellman, in Oura Bay.

633 349:344-358. doi: 10.1016/j.jembe.2007.05.024

634 Pollak N, Dolle C, Mathias Z (2007) The power to reduce: pyridine nucleotides-small

635 molecules with a multitude of functions. Biochemical Journal 402:205-218.

636 Roach TNF, Abieri ML, George EE, et al (2017) Microbial bioenergetics of coral-algal

637 interactions. PeerJ 5:e3423.

638 Russell JB, Cook GM (1995) Energetics of bacterial growth: balance of anabolic and

639 catabolic reactions. Microbiological Reviews 59:48-62.

640 Sauer U, Eikmanns BJ (2005) The PEP - pyruvate - oxaloacetate node as the switch

641 point for carbon flux distribution in bacteria. FEMS Microbiology Reviews 29:765-

642 794. doi: $10.1016 /$ j.femsre.2004.11.002

643 Silva G, Dutilh B, Edwards R (2016) FOCUS2: agile and sensitive classification of

644 metagenomics data using a reduced database. bioRxiv 46425.

645 Silveira C, Cavalcanti G, Walter J, et al (2017a) Microbial processes driving coral reef

646 organic carbon flow. FEMS microbiology reviews 41:575-595. doi:

$647 \quad 10.1093 /$ femsre/fux018

648 Silveira CB, Gregoracci GB, Coutinho FH, et al (2017b) Bacterial community associated

649 with the reef coral Mussismilia braziliensis's boundary layer over a diel cyle.

$650 \quad$ Frontiers in Microbiology 8:e784.

651 Silveira CB, Silva-Lima AW, Francini-Filho RB, et al (2015) Microbial and sponge loops

652 modify fish production in phase-shifting coral reefs. Environmental Microbiology

$653 \quad 17: 3832-3846$.

654 Smith JE, Brainard R, Carter A, et al (2016) Re-evaluating the health of coral reef

655 communities: baselines and evidence for human impacts across the central Pacific.

656 Proceedings of the Royal Society B: Biological Sciences 283:20151985.

657 Somera TM, Bailey B, Barott K, et al (2016) Energetic differences between 
bacterioplankton trophic groups and coral reef resistance. Proceedings of the Royal Society B: Biological Sciences. doi: 10.1098/rspb.2016.0467

660 Spaans SK, Weusthuis RA, Oost J Van Der, Whitman B (2015) NADPH-generating

661 systems in bacteria and archaea. Frontiers in Microbiology 6:1-27. doi:

662 10.3389/fmicb.2015.00742

663 Steinhauser D, Fernie AR, Arau WL (2012) Unusual cyanobacterial TCA cycles: not 664 broken just different. Trends in Plant Science 17:503-509. doi:

665 10.1016/j.tplants.2012.05.005

666 Stettner AI, Segrè D (2013) The cost of efficiency in energy metabolism. Proceedings of 667 the National Academy of Sciences 110:9629-9630.

668 Tremblay P, Gori A, Maguer JF, et al (2016) Heterotrophy promotes the re-establishment 669 of photosynthate translocation in a symbiotic coral after heat stress. Scientific $670 \quad$ Reports 6:38112.

671 Tremblay P, Grover R, Maguer JF, et al (2012) Autotrophic carbon budget in coral tissue: a new 13C-based model of photosynthate translocation. The Journal of Experimental Biology 215:1384-1393.

674 Vallino JJ, Hopkinson CS, Hobbie JE (1996) Modeling bacterial utilization of dissolved 675 organic matter: Optimization replaces Monod growth kinetics. Limnology and 676 Oceanography 41:1591-1609. doi: 10.4319/1o.1996.41.8.1591

677 Vander Heiden MG, Cantley LC, Thompson CB (2009) Understanding the Warburg 678 effect: the metabolic requirements of cell proliferation. science 324:1029-1033. 679 Williams PJB, Raine RCT, Bryan JR (1979) Agreement between the C14 and oxygen 680 methods of measuring phytoplankton production-reassessment of the photosynthetic 681 quotient. Oceanologica Acta 2:411-416.

682 Wilson SK, Bellwood DR, Choat JH, Furnas MJ (2003) Detritus in epilithic algal matrix 683 and its use by coral reef fishes. Oceanography and Marine Biology: an annual 684 review 279-309.

685 686 


\section{Figures}

688

Organic carbon-oxygen decoupling in coral reefs

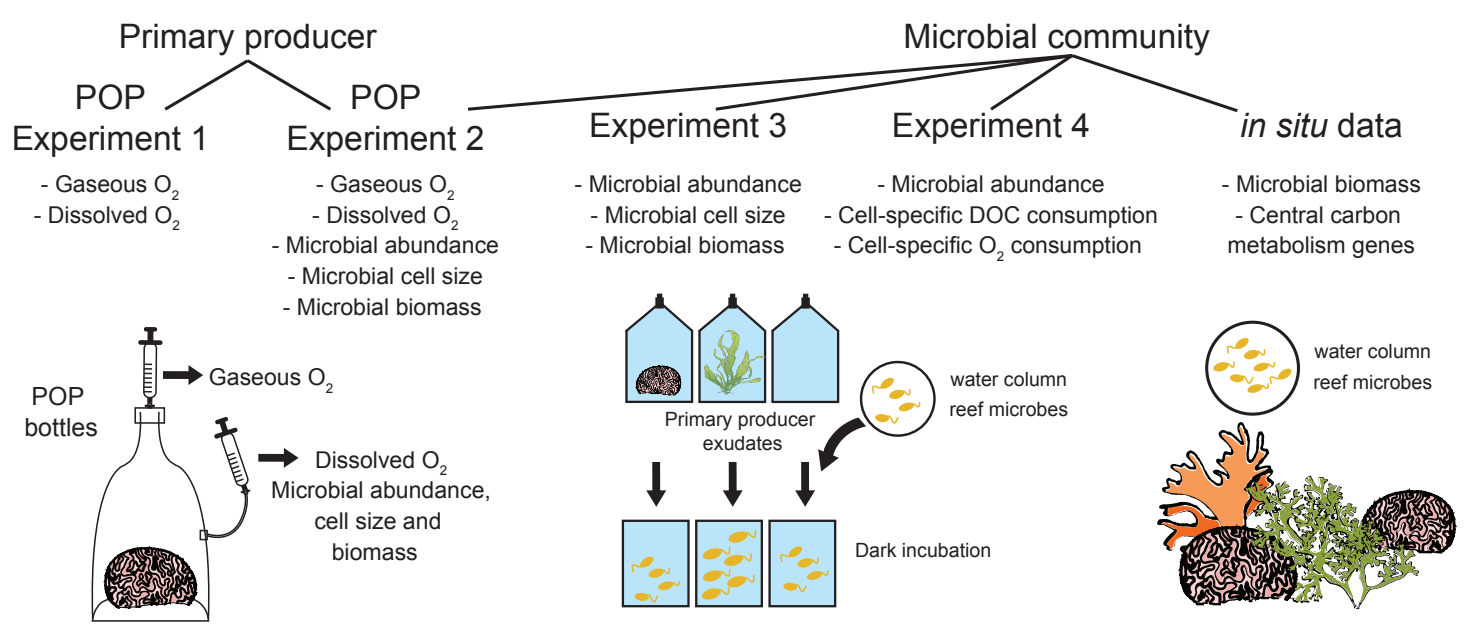
producer metabolism, and POP bottles utilized in the experiments are depicted. Microbial growth parameters were analyzed in POP Experiment 2 and dark incubations in Experiments 3 and 4. Microbial biomass and pathways for carbon metabolism were analyzed in reef water samples. The specific variables analyzed in each experiment are listed below experiment number. 

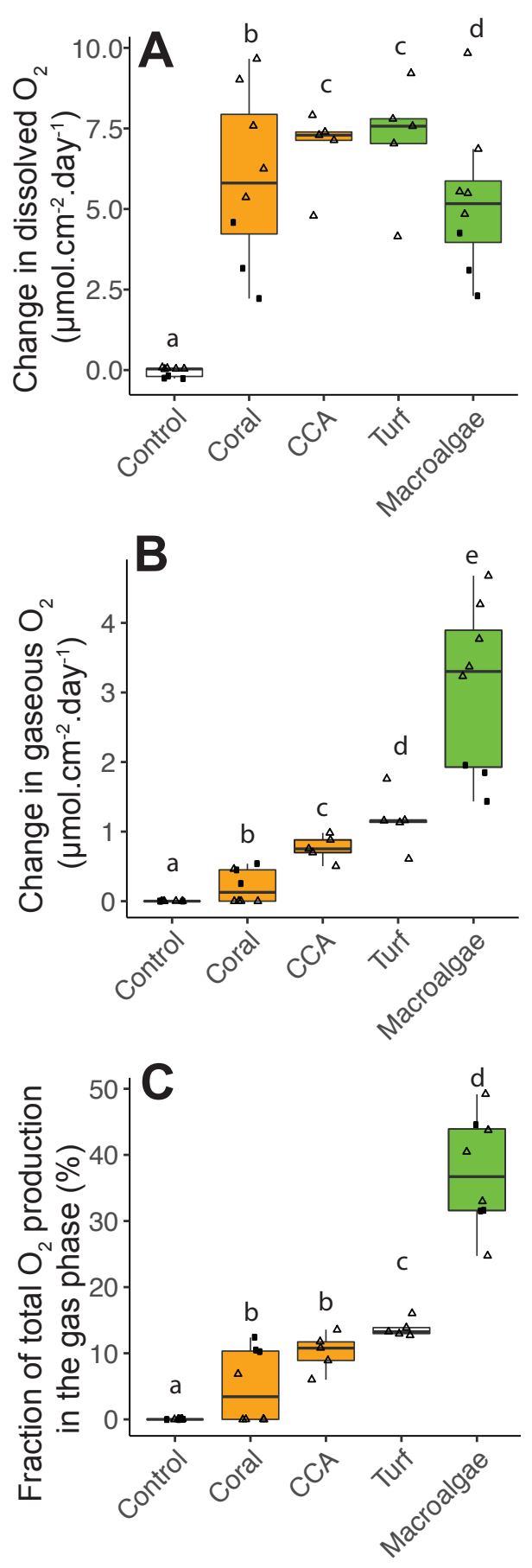

699 Figure 2. Photosynthetic $\mathbf{O}_{2}$ loss as gas from fleshy macroalgae. A) Dissolved $\mathrm{O}_{2}$

700 production rates normalized by organism surface area. B) Gaseous $\mathrm{O}_{2}$ production rates 701 normalized by organism surface area. C) Fraction of total photosynthetic $\mathrm{O}_{2}$ production 702 in the form of gas. Solid squares correspond to Experiment 1 and triangles to Experiment

703 2. Primary producer had a significant effect on all three variables (Kruskal-Wallis $\mathrm{p}<$ 704 0.05), and letters above boxes indicate $\mathrm{p}<0.05$ for Wilcoxon pairwise tests with FDR 705 correction. Orange indicate calcifying and green fleshy organisms. 

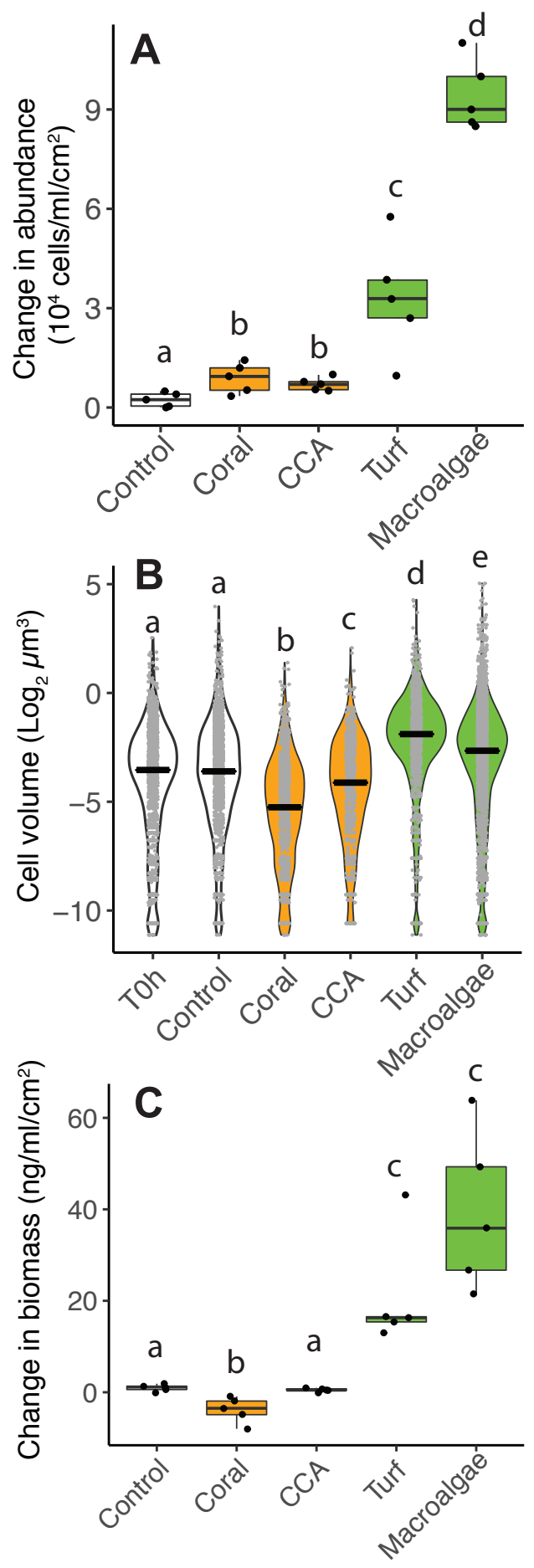
area. B) Cell volume distributions. C) Changes in total microbial biomass, accounting for abundance and cell volume, normalized by primary producer surface area. Primary producer treatments had a significant effect on all three microbial variables (KruskalWallis $\mathrm{p}<0.05$ ), and letters above boxes indicate $\mathrm{p}<0.05$ for Wilcoxon pairwise tests with FDR correction. Orange indicate calcifying and green fleshy organisms. 

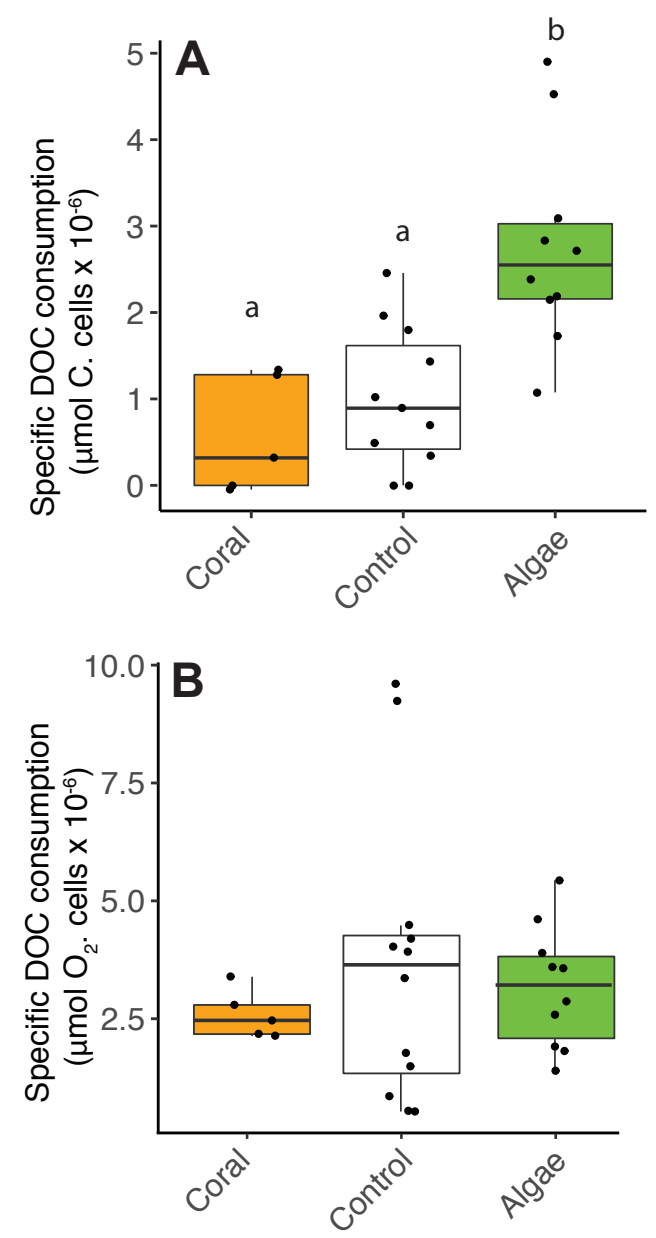

715 Figure 4. Decoupling between microbial DOC and $\mathbf{O}_{2}$ consumption in fleshy

716 macroalgae exudates. Cell-specific carbon and $\mathrm{O}_{2}$ consumption data from Experiment 4:

717 dark incubations of microbial communities in primary producer exudates. A) Cell-

718 specific DOC consumption. B) Cell-specific $\mathrm{O}_{2}$ consumption. Primary producer

719 treatments had a significant effect on specific DOC consumption only (Kruskal-Wallis $p$

$720<0.05)$ and letters above boxes indicate $\mathrm{p}<0.05$ for Wilcoxon pairwise tests with FDR

721 correction. Orange indicate calcifying and green fleshy organisms. 


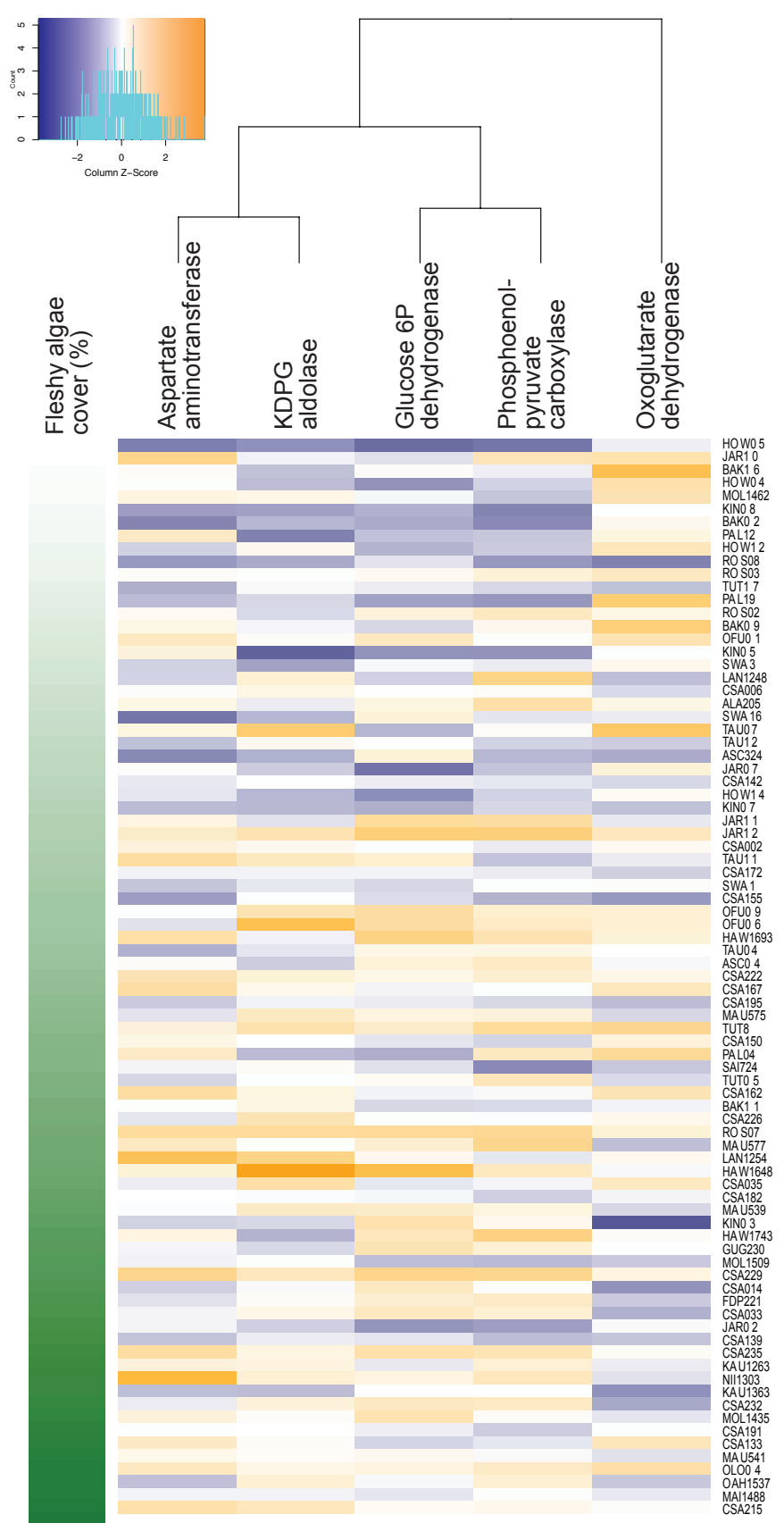

Figure 5. Increase in genes encoding anabolic pathways and decrease in genes encoding carbon oxidation reactions with fleshy algae cover in situ. Relative abundances of genes encoding rate-limiting enzymes in reef metagenomes are plotted in relation to fleshy algae cover (sum of fleshy turf and macroalgae). Individual metagenomes are listed as rows and sorted by the fleshy algae cover, ranging from 15 to $94.1 \%$. Enzyme abundance was scaled by column to allow between-enzyme comparisons. Only enzymes significantly predicting fleshy algae cover in the random 731 Supplementary Data 5. 
Figure 6. Metabolic decoupling model. Fleshy algal exudates have higher DOC: $\mathrm{O}_{2}$ ratios compared to corals. Heterotrophic bacteria respond to this difference by decoupling organic carbon consumption from oxidation: higher DOC consumption per cell with no increase in $\mathrm{O}_{2}$ consumption per cell. This metabolic change leads to accumulation of microbial biomass.
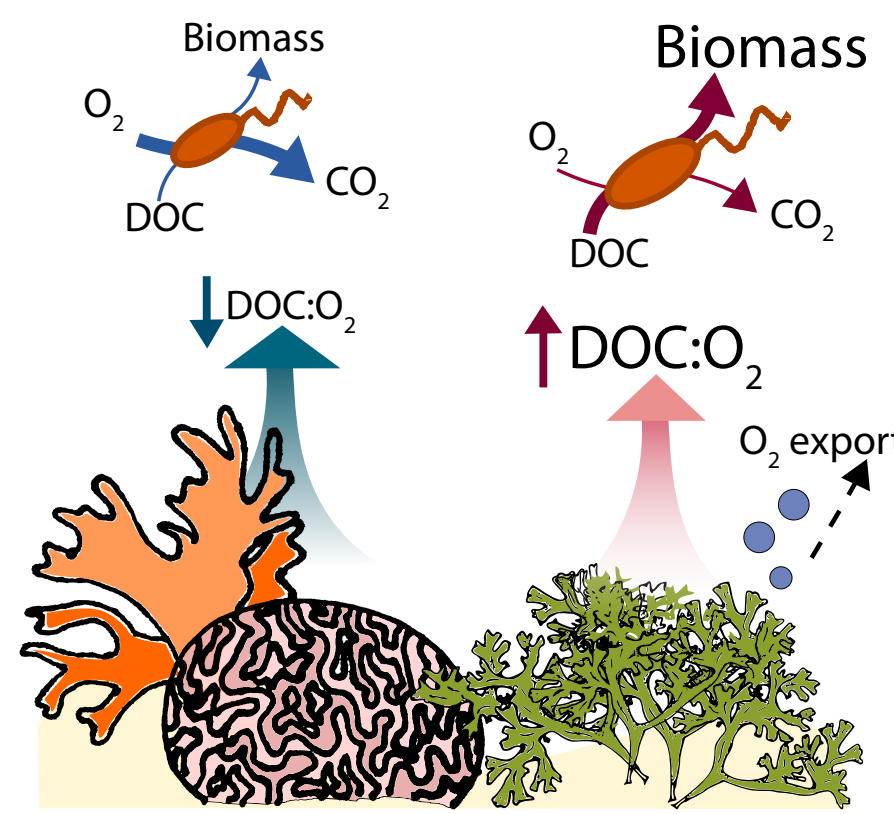